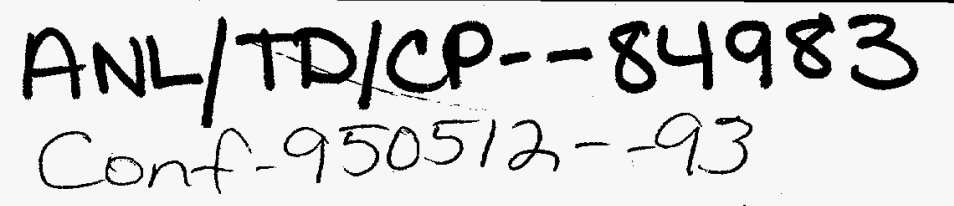

\title{
ACCELERATOR REQUIREMENTS FOR FAST-NEUTRON INTERROGATION OF LUGGAGE AND CARGO
}

\author{
B. J. Micklich, C. L. Fink, and T. J. Yule, Argonne National Laboratory, Argonne, IL 60439 USA
}

Several different fast-neutron based techniques are being studied for the detection of contraband substances in luggage and cargo containers. The present work discusses the accelerator requirements for fast-neutron transmission spectroscopy (FNTS), pulsed fast-neutron analysis (PFNA), and 14$\mathrm{MeV}$ neutron interrogation. These requirements are based on the results of Monte-Carlo simulations of neutron or gamma detection rates. Accelerator requirements are driven by count-rate considerations, spatial resolution and acceptable uncertainties in elemental compositions. We have limited our analyses to luggage inspection with FNTS and to cargo inspection with PFNA or 14-MeV neutron interrogation.

\section{INTRODUCTION}

Fast-neutron interrogation techniques are being examined for detection of illicit substances, such as explosives and narcotics, in luggage and cargo containers. Fast-neutron techniques are attractive because they can be used to determine the concentrations of the light elements [hydrogen, carbon, nitrogen, and oxygen] which are the primary constituents of these materials. Explosives and drugs are characterized by elemental densities and density ratios that are different from most other substances likely to be found in legitimate cargo.

This paper discusses two different fast-neutron techniques. The first uses an accelerator to produce nanosecond pulsed beams of deuterons that strike a target to produce a pulsed beam of neutrons with a continuum of energies. Elemental distributions are obtained by measuring the neutron spectrum after the source neutrons pass through the items being interrogated. This technique, first investigated by Overley [1] for bulk material analysis, is best suited for examination of luggage or small containers with transmissions greater than about 0.01 . The second technique uses an accelerator or sealed-tube source to produce monoenergetic fast neutrons. The characteristic gamma rays emitted due to fast- or thermal-neutron interactions with the material being interrogated allow the determination of elemental densities. Two variations[2,3] of this technique are considered here. This technique is suitable for examination of large containers because of the good penetration of the fast neutrons and the low attenuation of the high-energy gamma rays.

\section{FAST-NEUTRON TRANSMISSION SPECTROSCOPY}

Fast-Neutron Transmission Spectroscopy (FNTS) uses standard time-of-flight techniques to measure the energy spectrum of neutrons emitted from a collimated ${ }^{9} \mathrm{Be}(\mathrm{d}, \mathrm{n})$ continuum source before and after transmission through the sample. An unfolding algorithm determines the areal densities (density integrated along the line of sight, with units of number density per $\mathrm{cm}^{2}$ ), and the uncertainties, of the various elements present in the sample. Projection data from several angles are then reconstructed to provide two-dimensional images, one for each element, of a slice through the sample. The elemental reconstructions are then combined and processed through a detection algorithm. Only a few projections and coarse resolution are used to minimize interrogation time while still obtaining a reconstruction that provides enough separation between objects to maximize the success rate of an explosive detection algorithm. The use of this method as applied to explosive detection is discussed in Reference [4].

The accelerator requirements for an FNTS system involve tradeoffs between many parameters, including: the accelerator energy (size), the time available for sample examination, maximum allowable detector count rates, spatial resolution required for adequate explosive detection, and neutron yield and spectrum versus deuteron energy. There are also limits on how well elemental densities can be determined at lower deuteron energies. In general, one would like to have as high a detector count rate as possible to minimize sample irradiation time, consistent with acceptable errors due to dead time and spectral distortion. This limits the detector count rate to about one-tenth of the accelerator pulse repetition rate. Given a detector count rate, one can then determine the required neutron source rate from the lefthand side of

$$
R /(<T><\varepsilon>)=\text { source } n / s=S_{n} \Delta \Omega I_{p} \tau_{p} f
$$

$$
\begin{aligned}
& \text { where } \mathrm{R}=\text { maximum detector count rate } \\
& <\mathrm{T}>\text { = average transmission } \\
& \langle\varepsilon>=\text { average detector efficiency } \\
& \mathrm{S}_{\mathrm{n}}=\text { zero-degree neutron emission }(\mathrm{n} / \mathrm{sr}-\mathrm{s}-\mu \mathrm{A}) \\
& \Delta \Omega=\text { detector solid angle }(\mathrm{sr}) \\
& \mathrm{I}_{\mathrm{p}}=\text { pulse current }(\mu \mathrm{A}) \\
& \tau_{\mathrm{p}}=\text { pulse time width }(\mathrm{s}) \\
& \mathrm{f}=\text { accelerator pulse repetition rate }(1 / \mathrm{s})
\end{aligned}
$$

The right-hand-side of Eqn. [1] can then be used to determine the required accelerator current once the deuteron energy, pulse width, and pulse repetition rate have been chosen. A typical time-of-flight system would have a flight path of $5 \mathrm{~m}$, limiting $\mathrm{f}$ to $10^{6} / \mathrm{s}$ (to avoid wrap-around), thus making $\mathrm{R}=10^{5} / \mathrm{s}$. If the required spatial resolution inside the interrogated object is $2 \mathrm{~cm}$, the detector size would be $4 \mathrm{~cm}$ if 


\section{DISCLAIMER}

This report was prepared as an account of work sponsored by an agency of the United States Government. Neither the United States Government nor any agency thereof, nor any of their employees, makes any warranty, express or implied, or assumes any legal liability or responsibility for the accuracy, completeness, or usefulness of any information, apparatus, product, or process disclosed, or represents that its use would not infringe privately owned rights. Reference herein to any specific commercial product, process, or service by trade name, trademark, manufacturer, or otherwise does not necessarily constitute or imply its endorsement, recommendation, or favoring by the United States Government or any agency thereof. The views and opinions of authors expressed herein do not necessarily state or reflect those of the United States Government or any agency thereof. 


\section{DISCLAIMER}

Portions of this document may be illegible in electronic image products. Images are produced from the best available original document. 
the object is placed midway between source and detector. The required accelerator current as a function of deuteron energy is shown in Table 1 for transmission through $3 \mathrm{~cm}$ of RDX high explosive. While lower deuteron energies would lead to a smaller accelerator and thus smaller system footprint, the declining neutron yield means that more current is required.

Table 1. Deuteron current required for a neutron count rate of $10 \%$ in a $4-\mathrm{cm}$ detector as a function of deuteron energy (for $5 \mathrm{~m}$ flight path, $f=10^{6} / \mathrm{s}$, and $\langle\varepsilon\rangle=0.15$ ).

\begin{tabular}{|cccc|}
\hline$E_{d}(\mathrm{MeV})$ & $\mathrm{Y}_{\mathrm{n}}(\mathrm{n} / \mathrm{sr}-\mu \mathrm{C})^{\mathrm{a}}$ & $\left\langle\mathrm{I}_{\mathrm{d}}>(\mu \mathrm{A})^{\mathrm{b}}\right.$ & $\mathrm{I}_{\mathrm{p}}(\mathrm{mA})^{\mathrm{c}}$ \\
& & & \\
2.6 & $2.62 \cdot 10^{8}$ & 120 & 60 \\
3.0 & $4.35 \cdot 10^{8}$ & 69 & 35 \\
3.4 & $6.41 \cdot 10^{8}$ & 45 & 22 \\
3.8 & $8.83 \cdot 10^{8}$ & 31 & 16 \\
4.2 & $1.17 \cdot 10^{9}$ & 24 & 12 \\
4.6 & $1.50 \cdot 10^{9}$ & 18 & 9.1 \\
5.0 & $1.87 \cdot 10^{9}$ & 15 & 7.3 \\
5.4 & $2.31 \cdot 10^{9}$ & 12 & 5.9 \\
5.8 & $2.80 \cdot 10^{9}$ & 9.6 & 4.8 \\
6.2 & $3.35 \cdot 10^{9}$ & 7.9 & 4.0 \\
6.6 & $3.97 \cdot 10^{9}$ & 6.6 & 3.3 \\
7.0 & $4.66 \cdot 10^{9}$ & 5.6 & 2.8 \\
\hline
\end{tabular}

Neutron yield data from Ref. [5].

${ }^{b}$ Average deuteron current

${ }^{c}$ Peak deuteron current ( 2 ns pulse at $10^{6}$ repetition rate)

\section{PULSED FAST-NEUTRON ANALYSIS}

This technique uses nsec pulses of monoenergetic neutrons produced by accelerating deuterons onto a deuterium gas target. The neutron beam is scanned vertically across the cargo container by a movable collimator. Scanning along the length of the container is accomplished by moving the container horizontally. Depth information is obtained using time-of-flight between the accelerator pulse and the arrival of a gamma ray in Nal detectors located outside the container. Since the neutrons produced have velocities of about $4 \mathrm{~cm} / \mathrm{ns}$, the accelerator pulse must be at most a few ns if the voxel depth (thickness) is to be about $10 \mathrm{~cm}$. The $4.44-\mathrm{MeV}$ gamma from the first excited state in ${ }^{12} \mathrm{C}$ and the $6.13-\mathrm{MeV}$ gamma ray from the second excited state in ${ }^{16} \mathrm{O}$ are used to generate a qualifier that indicates the presence of drugs.

The signal obtained from this technique depends sensitively on the incident neutron energy used, as can be seen in Fig. 1. Neutron energies greater than $6.5 \mathrm{MeV}$ are required to detect ${ }^{16} \mathrm{O}$, with the optimum energy being between 8.2 and $8.25 \mathrm{MeV}$ (requiring a deuteron energy of about 5.0 $\mathrm{MeV}$. However, since the inelastic scattering cross sections vary rapidly in this energy range, the energy stability of the accelerator and the pulse-forming network which generates the nsec-width pulses must create an energy variation of less than $10 \mathrm{keV}$.

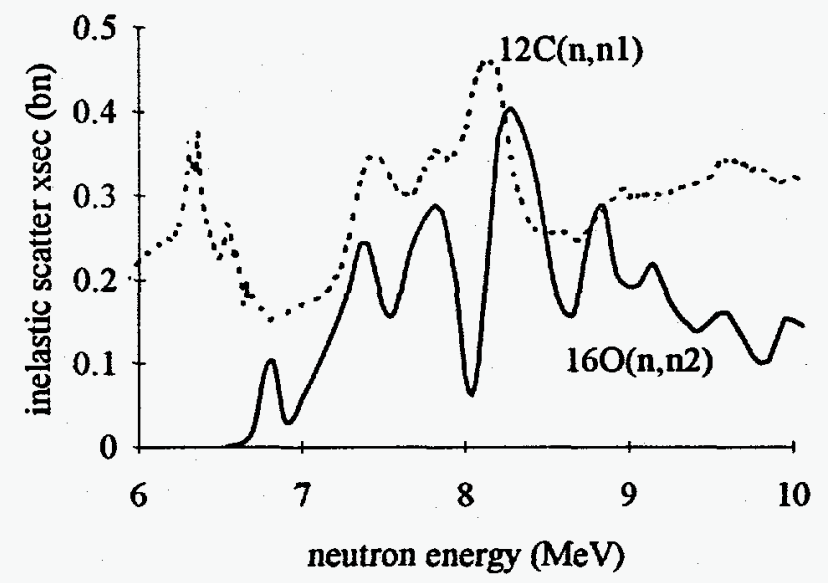

Figure 1. Inelastic scattering cross sections for the first excited state in carbon and second excited state in oxygen.

Equation 1 can be rewritten for PFNA in the form

$\left.R=\left\{\left\langle T_{n}\right\rangle\left\langle T_{\gamma}\right\rangle\right\}\left[S_{n} I_{p} \tau_{p} f \Delta \Omega_{n}\right]\left\{S_{\gamma} \Omega_{\gamma}\right\}<\varepsilon_{\gamma}\right\rangle$

where

$$
\begin{aligned}
& S_{\gamma}=\text { gamma source (gammas/sr-n) } \\
& \Omega_{\gamma}=\text { detector solid angle from gamma source } \\
& \left\langle T_{\gamma}\right\rangle=\text { average gamma transmission to detector }
\end{aligned}
$$

This is the same as Eqn. 1, with the factor $\left.\left\{\mathrm{S}_{\gamma} \Omega_{\gamma}\right\}<\mathrm{T}_{\gamma}\right\rangle$ added to account for the production and transport of gamma rays. We used the radiation transport code MCNP[6] to calculate the ${ }^{12} \mathrm{C}$ and ${ }^{16} \mathrm{O}$ gamma signals from a cargo container loaded with sugar at a density of $0.5 \mathrm{~g} / \mathrm{cm}^{3}$ with and without a ball of cocaine with radius $25 \mathrm{~cm}$ centered $75 \mathrm{~cm}$ from the front face. The count rates as a function of time are shown in Figure 2, and the count rates at the front of the sphere are given in Table 2. The actual count rates are obtained by multiplying the data in Table 2 by the estimated neutron source rates. For an average beam current of $100 \mu \mathrm{A}$, and a beam energy of $8.5 \mathrm{MeV}$, the number of neutrons incident on the region defined by the cocaine ball is $2.5 \cdot 10^{10} \cdot \Delta \Omega_{n} \cdot\left\langle\varepsilon_{p}\right\rangle$. Assuming that the ball occupies a solid angle of $0.023 \mathrm{sr}$ and that the gamma-ray detection efficiency is 0.2 , one calculates count rates of 74 and $43 \mathrm{cps}$ for the $C$ and $O$ lines in sugar, and 93 and $20 \mathrm{cps}$ for the $C$ and $O$ lines in cocaine.

The required number of counts to detect the difference in the $\mathrm{C} / \mathrm{O}$ ratios in sugar and cocaine will depend on the background and on the accuracy to which we need to know the ratio. If we assume a signal-to-background ratio of 1 , and a $20 \%$ accuracy in determining the $\mathrm{C} / \mathrm{O}$ ratio, then we will need approximately 300 counts in the ${ }^{16} \mathrm{O}(\mathrm{n}, \mathrm{n} 2)$ peak for the cocaine case. This implies a counting time of $300 / 12=15 \mathrm{~s}$. 

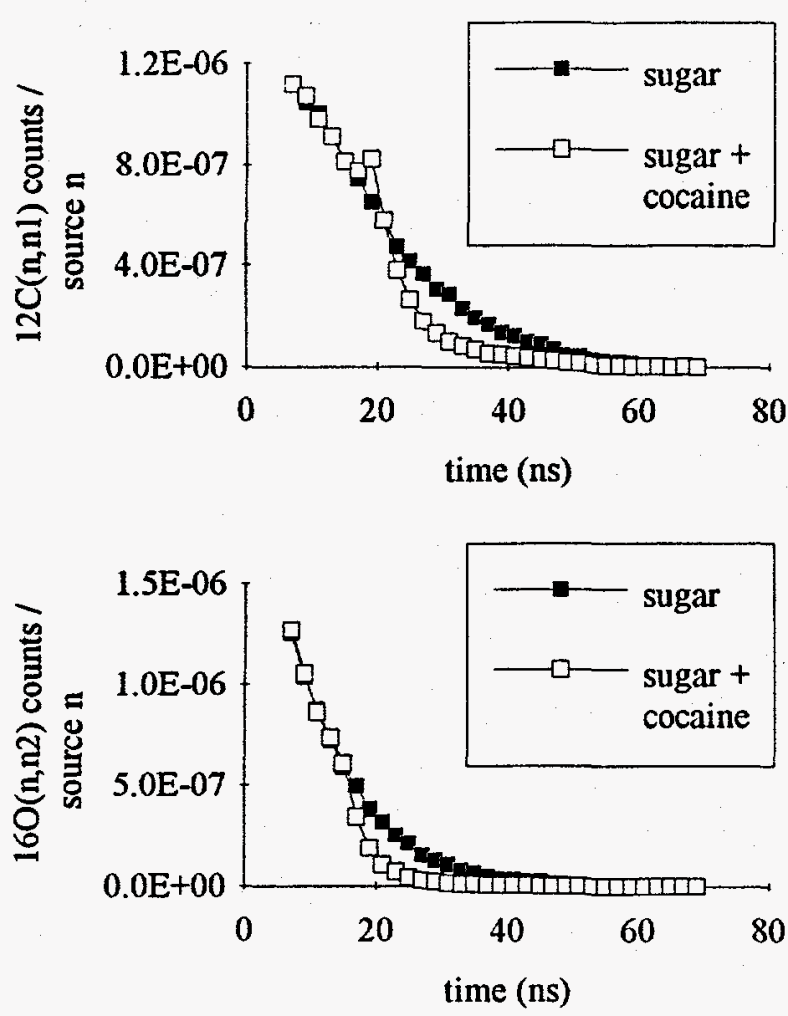

Figure 2. MCNP simulation results for 4.44-MeV gammas from ${ }^{12} \mathrm{C}$ (top) and $6.13-\mathrm{MeV}$ gammas from ${ }^{16} \mathrm{O}$ (bottom) detected at the middle of the top of a container containing sugar or sugar plus cocaine sphere.

Table 2. PFNA count rates for sugar and sugar + cocaine calculated with MCNP (normalized to 1 source $\mathrm{n} / \mathrm{s}$ ).

$\begin{array}{lcc} & \text { Sugar } & \text { Cocaine } \\ { }^{12} \mathrm{C}(\mathrm{n}, \mathrm{n} 1) & 6.5 \cdot 10^{-7} & 8.2 \cdot 10^{-7} \\ { }^{16} \mathrm{O}(\mathrm{n}, \mathrm{n} 2) & 3.8 \cdot 10^{-7} & 1.8 \cdot 10^{-7} \\ \text { Ratio } & 1.7 & 4.6\end{array}$

\section{14-MeV NEUTRON INTERROGATION}

In this technique 14-MeV neutrons are produced by a sealed-tube $(d, t)$ source. Collimators generate a fan-shaped neutron beam that illuminates a vertical slice of the cargo container. The horizontal position is varied by moving the cargo container. The vertical position and depth of the voxel are also defined by collimators, behind which are located the gamma-ray detectors. The neutron source is operated in a pulsed mode with each pulse lasting several tens of microseconds. The inelastic $4.44-\mathrm{MeV}$ and $6.13-\mathrm{MeV}$ gamma rays from carbon and oxygen are detected during the active portion of each pulse. Prompt activation gamma rays characteristic of chlorine and nitrogen (PGNAA - Prompt Gamma Neutron Activation Analysis) and capture gamma rays from hydrogen (DGNAA - Delayed Gamma Neutron Activation Analysis) are detected between pulses.
The same analysis that was applied to PFNA in Section III can be used for 14-MeV interrogation. While the source neutrons have slightly greater penetrability, the gamma ray signals are lower because the inelastic scattering cross sections are lower, about 0.2 bn for ${ }^{12} \mathrm{C}(\mathrm{n}, \mathrm{nl})$ and 0.1 bn for ${ }^{16} \mathrm{O}(\mathrm{n}, \mathrm{n} 2)$. These cross sections are flat in this energy region. The neutron source rates for these types of $(d, t)$ tubes are presently limited to approximately $8 \cdot 10^{9} \mathrm{n} / \mathrm{s} / \mathrm{sr}$ in the forward direction, which is lower than the $2.5 \cdot 10^{10} \mathrm{n} / \mathrm{s} / \mathrm{sr}$ assumed for PFNA. These tubes have the advantage of size and cost compared to an $8.5-\mathrm{MeV}$ accelerator. A major disadvantage is their limited lifetime.

\section{SUMMARY}

The accelerator requirements for FNTS are determined primarily by detector count rates and not by fundamental accelerator limits. The main requirement for accelerator designers is to reduce size and cost. For PFNA and 14-MeV neutron interrogation methods, the gamma-ray count rates are directly proportional to the accelerator current. These techniques could make use of increased accelerator current.

\section{ACKNOWLEDGMENTS}

This work was sponsored by the U. S. Federal Aviation Administration Technical Center under contract DTFA0303-X-00021 and by the Office of National Drug Control Policy, Counterdrug Technology Assessment Center under contract 6-CO-160-00-195.

\section{REFERENCES}

[1] J. C. Overley, J. Appl. Radiat. Isot. 36 (1985); Nucl. Instr. Meth. Phys. Res. B24/25 (1987).

[2] Z. P. Sawa and T. Gozani, Proc. 1st Int'l Symp. on Explosive Detection Technology, Atlantic City, NJ (May 1992); D. L. Brown, R. Loveman, J. Bendahan, and M. Schulze, Proc. Int'l Symp. on Contraband and Cargo Inspection Technology, Washington, DC (Oct. 1982).

[3] M. J. Hurwitz, R. C. Smith, W. P. Noronha, and K.C. Tran, Proc. Int'l Symp. on Contraband and Cargo Inspection Technology, Washington, DC (Oct. 1992).

[4] B. J. Micklich, A. H. Novick, M. K. Harper, and D. L. Smith, Nucl. Instr. Meth. Phys. Res. A353 (1994); C. L. Fink, B. J. Micklich, T. J. Yule, P. Humm, and L Sagalovsky, 13th Int'l Conf. on the Application of Accelerators in Research and Industry, Denton, Texas (Nov. 1994).

[5] J. W. Meadows, "The Thick-Target ${ }^{9} \mathrm{Be}(\mathrm{d}, \mathrm{n})$ Neutron Spectra for Deuteron Energies Between 2.6 and 7.0 MeV," Nucl Instr. Meth. Phys. Res. A324 (1993).

[6] "MCNP - A Generalized Monte Carlo Code for Neutron and Photon Transport, Version 3A," LA-7396-M, Rev. 2, Los Alamos National Laboratory (Sept. 1986). 